International Journal of Child, Youth and Family Studies (2013) 1: 100-118

\title{
STEPPING UP: A PEER-TO-PEER DATING VIOLENCE PREVENTION PROJECT ON A POST-SECONDARY CAMPUS
}

\section{Gaye Warthe, Patricia Kostouros, Cathy Carter-Snell, and Leslie M. Tutty}

\begin{abstract}
The purpose of the Stepping Up project was to develop, implement, and evaluate a peer-facilitated dating violence prevention program for post-secondary students. Phase I of the program focused on recruiting and training student peerfacilitators, adapting the curriculum for a post-secondary population, developing the evaluation measures, ethics clearance, and establishing community partners and an advisory committee. Phase II included recruiting participants, implementing Stepping Up and completing pre, post, and follow-up measures. To consolidate learning the students then completed prevention projects and presented them to the university campus community. Repeated evaluations showed that students had increased knowledge about dating violence and resources and these changes persisted over time. Use of peers as facilitators and community partner involvement contributed to success. Challenges included scheduling the weekend, the time commitment for facilitators and participants, and project resources. Stepping Up is compatible with an academic setting with benefits for both the students and the institution.
\end{abstract}

Keywords: dating violence, post-secondary students, prevention, education, peer training

Acknowledgements: This particular project was funded through the Centre for Criminology and Justice Research (CCJR) and the United Way of Calgary and area.

D. Gaye Warthe, MSW, Ph.D., (the Corresponding Author) is an Associate Professor and Chair of the Department of Social Work and Disability Studies at Mount Royal University, 4825 Mount Royal Gate SW, Calgary, Alberta, Canada, T3E 6K6. E-mail: gwarthe@mtroyal.ca

Patricia Kostouros, Ph.D. is an Associate Professor, Department of Child and Youth Studies at Mount Royal University. E-mail: pkostouros@mtroyal.ca

Cathy Carter-Snell, RN, Ph.D. is an Associate Professor, Department of Advanced Specialties in Health at Mount Royal University. E-mail: ccartersnell@mtroyal.ca

Leslie M. Tutty, Ph.D. is a Professor with the Faculty of Social Work at the University of Calgary, 2500 University Drive NW, Calgary, Alberta, Canada, T2N 1N4.

E-mail: tutty@ucalgary.ca 
The Stepping Up project was created as a pilot peer-facilitated dating violence prevention program for post-secondary students at a western Canadian university. Warthe and Tutty's (2008, 2010) research has addressed the importance of student-to-student interaction since young people tend to approach their peers when in need of assistance. Peers who understand the dynamics of dating violence can make appropriate referrals, thereby intervening to reduce dating violence in people's lives, and on their campuses. The following examples are based on true incidents related to post-secondary students who experienced dating violence or had a connection to the dating violence project described in this article. The names and facts have been altered by using pseudonyms and changing other identifying information such as age and gender. These examples serve to illustrate the nature of dating violence on post-secondary campuses and the importance of peer-facilitated programs.

Tracey is a 20-something student peripherally involved with the university student association. Tracey had been approached by a fellow student, Jennifer, who was aware that Tracey knew of resources for students in need. Jennifer had bruises on her arms and face and explained that her boyfriend, who was also the son of her landlord, had physically abused her. Tracey immediately referred Jennifer to the campus resources and followed up with her over the next few days. Jennifer is safe, in a new residence, and is thankful that someone knew what she needed.

Tracey felt confident that she had intervened appropriately because she had seen the community prevention projects created by participants in the Stepping Up program. These projects were part of a campus awareness campaign in relation to dating violence prevention and intervention delivered by participants and peer-facilitators of Stepping Up. Tracey had spoken with peer-facilitators about the project, during the campaign, and had gained awareness about the appropriate resources, on campus and off, for dating violence intervention.

David, a 20-something young man and a peer-facilitator in the Stepping Up project, was approached by a professor seeking to learn more about the project. David's professor was aware of the statistics having seen a play that the peer-facilitators had performed for faculty members. David's professor wondered how to intervene when students showed signs of intimate partner violence, especially being aware of the precariousness of dual relationships between faculty and students on post-secondary campuses. He supported the rationale of having students talk with their peers about dating relationship problems.

Dating violence consists of the application of force or control by at least one member of an unmarried or non-common-law couple, and may include emotional, psychological, spiritual, physical, or sexual forms of coercion. Sexual assault is any non-consensual contact of a sexual nature. Sexual abuse is repetitive sexual assault (Warthe \& Tutty, 2009). North American studies reflect that as many as $76 \%$ of women and $85 \%$ of men attending post-secondary institutions experienced physical, psychological, or sexual violence in romantic or dating relationships (Amar \& Gennaro, 2005; Forbes \& Adams-Curtis, 2001; Simonelli, Mullis, Elliott, \& Pierce, 2002; Smith, White, \& Holland, 2003). In January of 2008, and again in 2010 at this particular western Canadian university, Warthe and Tutty $(2008,2010)$ added questions on dating violence 
International Journal of Child, Youth and Family Studies (2013) 1: 100-118

to the National College Health Assessment survey (NCHA), that were answered by a randomly selected sample of students. In both 2008 and 2010, approximately one in three undergraduate students at this specific campus had experienced some form of dating violence within the 12 months preceding the survey: $9 \%$ of women and $4.8 \%$ of men in 2008 . In 2010, $11 \%$ of women and $6 \%$ of men had been stalked and $14 \%$ of women and $10 \%$ of men disclosed having been emotionally abused in the previous 12 months.

The consequences of dating violence can be life changing and even fatal (Campbell et al., 2003). Studies specific to dating violence recognized the consequences of emotional, physical, and sexual violence, and noted decreasing academic performance or career achievement, substance use, unhealthy weight control behaviours, risky sexual behaviours, mental health disorders, pregnancy, chronic health diseases, post-traumatic stress, suicidal ideation, and the risk of violence in future relationships (Amar, 2007; Amar \& Gennaro, 2005; Danis \& Anderson, 2008; McFarlane et al., 2005; Silverman, Raj, Mucci, \& Hathway, 2001; Straus, 2004; Straus \& Savage, 2005; Walton-Moss et al., 2003; Warthe \& Tutty, 2009). A study at this particular university showed that female students having recent experiences of violence were more likely to disclose depression, anxiety disorder, substance abuse problems, and at least one attempted suicide within the same period (Warthe \& Tutty, 2009). Surveys completed at this campus showed that students who disclosed dating violence were also at greater risk of sexual violence including sexual touching, attempted penetration (i.e., vaginal, oral, and/or anal), and sexual penetration against their will (Warthe \& Tutty, 2009, 2010).

Post-secondary students are at particular risk of dating violence for a number of reasons. Given that one of the developmental tasks at this age is to find a life partner (Arnett, 2004; Erikson, 1985), there is more potential for pressure to be in a relationship and a greater likelihood of more intimate relationships than in high school populations. In addition, Johnson (2006) reported that adolescents and young adults are in the age group likely to experience the highest rates of violence and the most serious forms of violence including sexual assault, stalking, serious spousal assault, and spousal homicide in intimate partner relationships. While there is much to say about the theoretical underpinnings related to the prevalence of such rates, the focus of this article is on the development and implementation of a dating violence prevention program for a post-secondary campus.

The prevalence and consequences of dating violence among post-secondary students highlighted the urgent need to develop and implement dating violence prevention initiatives appropriate to this age group. In spite of overwhelming evidence that prevention programs are necessary, evaluated dating violence prevention programs for post-secondary students are largely absent from the literature (Danis \& Anderson, 2008; Tutty et al., 2005).

\section{Purpose}

The Stepping Up project focused on implementing and evaluating a peer-facilitated program to prevent and reduce the incidence of dating violence among post-secondary students at this particular western Canadian university. The key research questions were related to two areas: (a) Were there changes in attitudes and behaviours, post-program? (b) How effective was the program? Based on limited data and the researchers' experiences and knowledge in the area 
International Journal of Child, Youth and Family Studies (2013) 1: 100-118

of intimate partner violence, three main research questions were developed specific to the Stepping Up program:

1. Are there changes in students' knowledge, attitudes and behaviours or behaviour intent regarding dating violence and resources available?

2. What factors affected the students' satisfaction?

3. What aspects of the program require modification?

Despite the significant risks and consequences of dating violence suggested previously, there is a notable gap in the resources and knowledge related to dating violence among post-secondary students (Warthe \& Tutty, 2008). Existing dating violence prevention programs that have been evaluated are for younger populations and do not include content related to sexual violence aimed at a post-secondary population.

The need for dating violence prevention in the post-secondary setting is further heightened by the lack of availability of such programming for junior and senior high school students as noted in one Canadian study (Warthe, Hoffart, \& Cooper, 2004). Post-secondary students are entering into university settings with limited knowledge about dating violence. Governmental and community initiatives on family violence and bullying have addressed either couples living together (e.g., spousal abuse, domestic violence), or acts of bullying or relational aggression between children or teens. There is a need for a primary prevention program specific to young adults (Warthe et al., 2004).

The goal of primary prevention is to stop violence before it occurs. The questions of when and with what population to insert prevention programs are central to prevention efforts. It may be possible to prevent, and potentially drastically reduce, the incident rate of violence in future and long-term relationships, as well as to mitigate the consequences from prior abuse if youth and young adult relationship violence is addressed (Wolfe et al., 2003). According to Warthe (2011) the links between family violence and dating violence highlights the need to focus prevention efforts on adolescents and emerging adults as they commence dating relationships. It presents an effective and efficient approach to preventing future intimate relationship violence. However, it is important to note that based on the experience of adolescent prevention programs, brief one-time information sessions are not likely to change attitudes that support violence and prevent violent behaviour over the long term (Tutty \& Bradshaw, 2003; Tutty et al., 2005). Prevention activities that are part of a continuum provide for the repetition of information using diverse formats, in different contexts, reducing the likelihood of "erosion of knowledge" (Legge, Josephson, Hicks, \& Kepron, 2004, p. 75).

Given the argument presented above related to the need for programs for post-secondary students at the dating stage, this particular project, Stepping Up, was unique as a dating violence prevention program with the potential to prevent abuse by addressing both risk and resiliency factors. The project had a strong evaluative component and involved students not only as participants, but also as peer-facilitators and as advising partners actively addressing curriculum development and evaluation. 
International Journal of Child, Youth and Family Studies (2013) 1: 100-118

\section{Project Design}

The Stepping Up project is a prospective longitudinal study, with repeated measures of behaviours, knowledge, and attitudes toward dating violence before and after participation in a dating violence prevention project. Stepping Up is based on Making Waves/Vague par vague (Making Waves), developed in New Brunswick in 1995 for high school students and was developed in collaboration with women's shelter programs in New Brunswick. Those involved in the New Brunswick Women's Shelters had a desire to impact the youth of their community in order to decrease violence at a younger age (Tutty, 2010). Making Waves is supported by Canada's Department of Justice (Department of Justice, 2003) and has been identified as producing long-term changes in participants' attitudes and experiences related to dating violence (Cameron et al., 2007; Tutty et al., 2005; Tutty, 2010).

Making Waves comprises an interactive weekend workshop with a drama presentation and discussion groups, followed by completion of a community violence prevention project related to dating violence in the months following the weekend program. The weekend workshop content addressed healthy relationships, forms of dating violence, gender stereotypes, media influences, issues of power and control, and skill development (Cameron et al., 2007). The Making Waves violence prevention project is conducted in the participant's community and is aimed at supporting attitude and behaviour change and increasing awareness of violence in the community. Particular strengths of the program, in addition to attitude and behaviour changes, include peer facilitation and follow-up projects by participants. Making Wave follows a particular model for selection and training of peer-facilitators not described in this article, since we were unable to follow the same precise model for this project.

Peer facilitation, combined with community support, is a key factor in prevention especially if the materials are made relevant to the participants' context (Casey \& Lindhorst, 2009). The additional expectation of a community project may help students integrate and consolidate learning in addition to benefiting the larger community. Designed for a high school population with a lack of information on sexual violence limited the possibility of choosing the Making Waves program for post-secondary students (Tutty, 2010).

The social-ecological model of prevention was chosen as a guiding framework for this project leading to curriculum modifications and structure (Centre for Disease Control, 2007). This model is used by both the World Health Organization and the Centre for Disease Control as an effective method by which to address primary prevention. The Stepping Up project addressed the four components of the ecological model: individual, relationship, community, and society. Examples of these components as applied to a dating violence prevention curriculum include the following:

1. Individual - vulnerability (e.g., self-esteem, gender, incapacitation with drugs/alcohol), self-protective behaviours, risks;

2. Relationships - healthy relationships, power and control, conflict resolution;

3. Community - sources for seeking help, role of bystander or peers (i.e., social responsibility); and 
International Journal of Child, Youth and Family Studies (2013) 1: 100-118

4. Society - the role of myths (e.g., relationships or sexual assaults) and gender stereotypes (e.g., masculinity).

These components were also incorporated at a program delivery level. The program was aimed at facilitating changes in individuals and their relationships. The community was actively involved, with a number of advisory members and project partners. Their involvement demonstrated the commitment of the university and the external community to the prevention of dating violence and the willingness to seek social change. Development of a critical mass of people with awareness and capacity related to dating violence prevention, coupled with the use of peer group facilitators, has the potential to effect wider social change.

The Stepping Up project was supported by other ongoing and planned initiatives that were aimed at promoting social change. This included the biannual survey of students at this western Canadian campus on the incidence and prevalence of dating violence, "Turn off the Violence” activities each November, and the development of credit curriculum on violence and violence prevention through the lifespan. There are also long-term opportunities for the development of screening protocols for counselling and health services and workplace policies supporting students, staff, and faculty dealing with current issues of domestic violence. All of these activities contribute to social change and to a culture that supports such violence prevention initiatives as Stepping Up.

External community involvement was strong as well. Approximately seven external agencies, (in addition to internal campus supports), became involved in the project, either as advisory members or as partners. Partners were more actively involved by participating as peerfacilitator trainers and content experts for the development of module content and for peer support during the weekend delivery. Community partners took an active role in supporting the peer-facilitators, as well as providing access to their services if required by students. Advisory members were invited to provide feedback early in the project and assisted the researchers in linking the materials being delivered to what was being expressed in the community with respect to needed prevention and intervention. Both partners and advisory committee members represented a range of dating violence and sexual assault services and expertise both within the campus and the broader community, and included student representatives. This project was divided into three phases: development, implementation and evaluation, and revision.

\section{Phase I: Development}

The development phase of the Stepping Up project included recruitment and training of 16 peer-facilitators, the development of curriculum and evaluation measures, and engagement of the advisory committee and community partners (described later in this article). Prospective peer-facilitators were invited to one of several information meetings hosted by the researchers. To increase the likelihood that peer-facilitators would have the skills and attitudes consistent with the project, faculty were asked to identify and refer appropriate students to the information meetings. During the initial meeting, interested students were asked to complete an application indicating availability on pre-scheduled dates, and interest in dating violence. As noted, 16 students declared an interest in the role and their availability on the designated training dates and one student indicated interest in assisting with the play. Students were predominantly from the 
International Journal of Child, Youth and Family Studies (2013) 1: 100-118

Social Work and Child and Youth Studies programs, in addition to single members from Nursing, Sociology, Psychology, Theatre, and Open Studies.

Curriculum development and training of the peer-facilitators occurred simultaneously and reflected a process orientation. Using the module categories utilized by Making Waves, with an additional module on sexual relationships, students were asked to brainstorm what topics or issues might be included in the module. From the expansive lists that were developed, students identified the top two or three issues relevant for post-secondary participants. Peer-facilitators, community partners, and researchers all participated in this process with the partners and researchers in the role of consultants. This first training exercise required six hours and included discussions on myths, types of abuse, gender roles, communication barriers, safety, consent, attribution of responsibility, and resources. This session was facilitated by the researchers and included both small (3 to 4) and large (16 to 20) group discussions.

Additional training included a full day with the National Coordinator for Making Waves/Vague par vague (Making Waves) from Partners for Youth Inc., who demonstrated activities and exercises used in Making Waves and time spent with a forensic nurse who developed a peer-facilitated initiative in New Orleans called Girls Not Gone Wild. Both of these sessions included opportunities for the peer-facilitators to express their ideas and thoughts on what had been presented and to ask questions of the consultants. Modules were developed based on the issues and priorities identified by the peer-facilitators in the training.

The evaluation framework and measures were developed and funding was solicited for Phase II of the project. The Dating Relationship Scale (Warthe, 2011) and the Knowledge Attitude, and Behavioural Intentions (KABBI) (adapted from the Making Waves project), and the module evaluation survey comprised the measures used in the project. Community members were asked to participate in the project through the advisory committee and were given an early opportunity to provide input on the model and modules being developed.

\section{Phase II: Implementation and evaluation}

This pilot was designed to accommodate a total of 60 undergraduate students with an even division of women and men. This number was based on the number used consistently in the Making Waves program. A group of 60 provides 15 participants in each of the concurrently run modules. Students 18 years of age and older were eligible for inclusion in the pilot project. Recruitment of student participants began as soon as ethical clearance was obtained from the university's Human Research Ethic Board (HREB), in December 2010. Information on the Stepping Up project and opportunities to participate were provided to all students at this campus using existing communication strategies such as the intranet, through program advisors, student societies (e.g., Sociology Student Society, Psychology Student Society) and through the campus Student Association. The peer-facilitators also took an active role in encouraging their peers to participate.

The majority of the students attending the pilot were from programs and faculties that actively supported the Stepping Up project. For some students, such as those from Social Work 
International Journal of Child, Youth and Family Studies (2013) 1: 100-118

and Child and Youth Care Counselling, rewards were offered for attendance; specifically, hours spent on the project counted towards training and/or credit for volunteer activities.

The Stepping Up project held its first pilot prevention weekend January 28 to 30, 2011. As with the Making Waves program, the weekend included a drama presentation on the Friday evening, a full day of workshops (modules) on the Saturday, and a half day on Sunday to begin the planning process for community prevention projects. Participants, with the support of the assigned peer-facilitators, completed the community prevention projects in April when they were displayed to the campus community. A variety of community projects consisted of such items as brochures, games, or t-shirts. Each student had a nominal budget to spend, which assisted in the completion of the project, and several students formed groups that allowed their funds to go further and assist in accountability for completion. The eight-month follow-up evaluation was completed in October 2011 and early results have been tabulated.

\section{Phase III: Revision}

As this article was in preparation, Phase III was underway and will incorporate the feedback provided by community partners, peer-facilitators, and the researchers' own understanding of needed changes. Completion of Phase III of this project is expected in the Fall of 2012.

\section{Results}

Initial registration for the Stepping Up weekend was 50 undergraduate students at the western Canadian university campus. However, competing demands and a severe snowstorm resulted in decreased participation. Stepping Up participants were asked to complete measures prior to participation in the prevention weekend, January 28 to 30, 2011. Each respondent developed their own unique identifier to ensure anonymity and confidentiality. Respondents completed the Dating Relationship Scale (Warthe, 2011), and the KABBI. Participants, who had not completed the measures online prior to the weekend, completed them at registration.

Demographics. In total, 30 students completed all, or part, of the Dating Relationship Scales. Respondents were predominantly women (66.7\%), single (70\%), aged 19 to 57 years (43\% less than 24 years; 33\% 25 to 29 years), and 36\% identified as belonging to diverse communities (63\% White). Almost half of all respondents had experienced at least one type of abuse or violence in one or more previous relationships with $48 \%$ reporting being the victim of verbal and emotional abuse, 33\% physical abuse, and 30\% sexual abuse. When asked about experiences of witnessing or being the recipient of abuse as a child or adolescent in their home, $48 \%$ indicated that they had witnessed violence between adults as children.

Module evaluations. Participants were asked to complete evaluations after each of four modules. The four modules were rated on five-point scales with very positive results (Table 1). Module ratings range from 4.52 to 4.71 . 
International Journal of Child, Youth and Family Studies (2013) 1: 100-118

Table 1. Module Evaluations

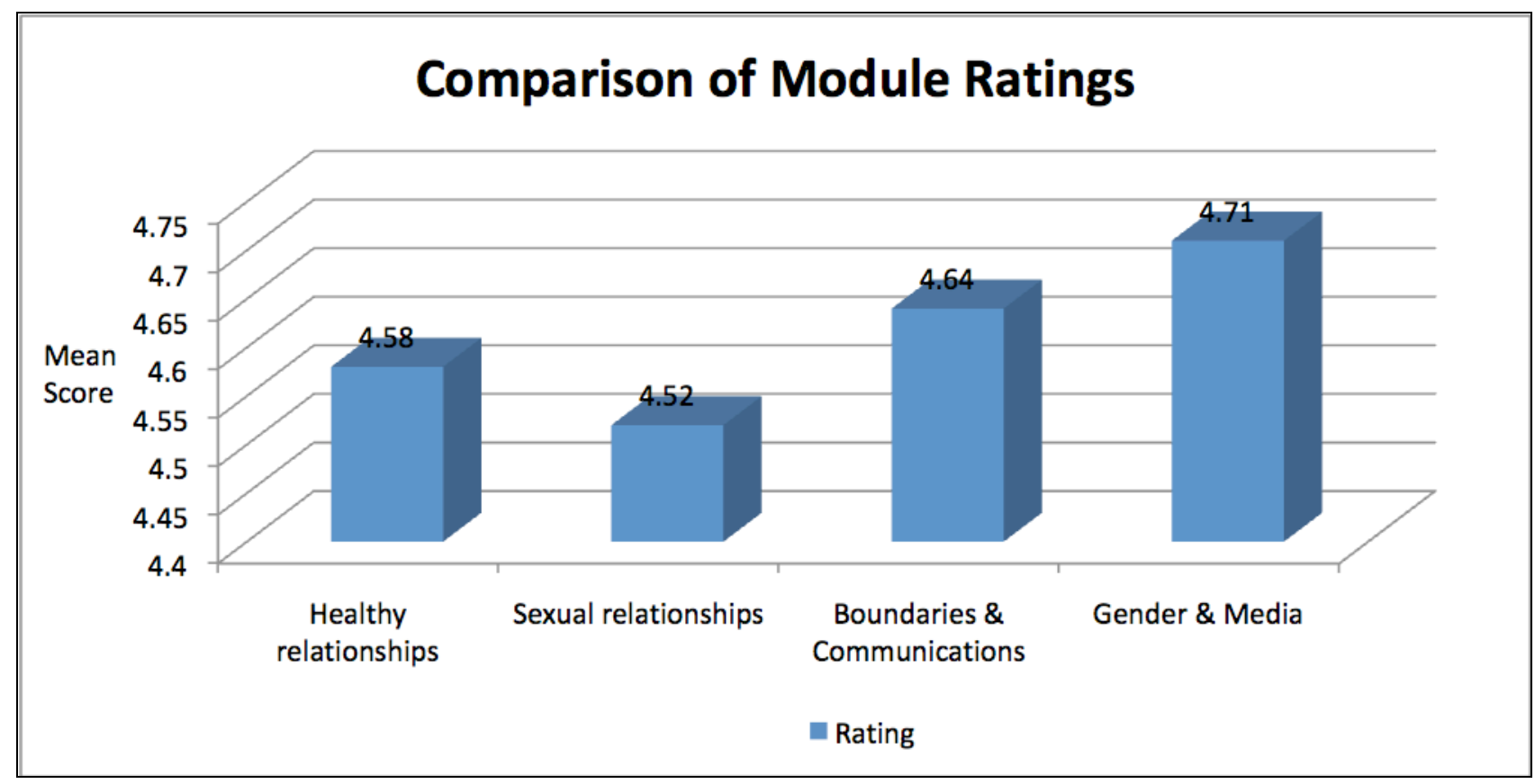

In the module evaluations, participants indicated that they liked: the opportunity to talk with others, the peer-facilitators, videos that were used in the modules, learning about resources, and the role-plays. Participants recommended more time for each module (without increasing the length of the weekend), more discussion, less role-playing, different videos, and the need for concrete tools.

Knowledge, Attitudes, and Behaviour/Behaviour Intent (KABBI). Participants completed the KABBI prior to and immediately following the prevention weekend. Among those who completed both the pre and post KABBI $(n=11)$, mean scores improved for knowledge in all key areas, with large effect sizes particularly for knowledge of community domestic violence resources, sexual assault resources, knowing how to intervene, and personal boundaries (Table 2). 
International Journal of Child, Youth and Family Studies (2013) 1: 100-118

Table 2. KABBI Pre and Post Knowledge Scores

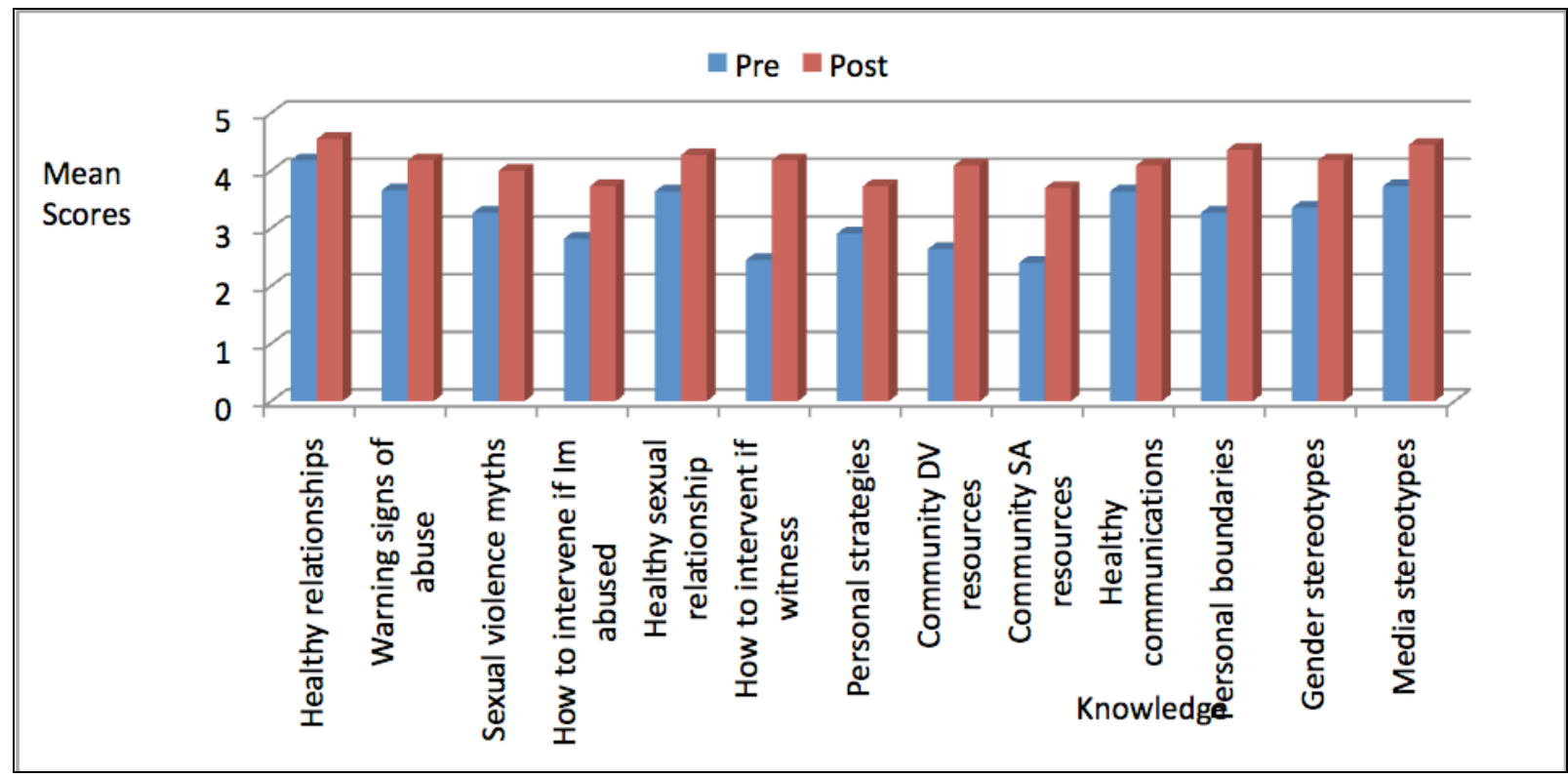

The KABBI was repeated at a point eight months following the Stepping Up prevention weekend and the increases in knowledge that were noted immediately following the Stepping Up prevention weekend were sustained up to the eight-month interval on almost all parameters. The largest differences between the period before the workshop and eight-month interval include the warning signs of abuse, interventions to reduce dating violence, healthy versus unhealthy sexual relationships, how to intervene if one witnesses or learns of dating violence, personal strategies to reduce dating violence, community resources to assist with dating violence, and community resources to assist with sexual violence (Table 3). 
International Journal of Child, Youth and Family Studies (2013) 1: 100-118

Table 3. KABBI Pre, Immediate Post, and Eight-Month Knowledge Scores

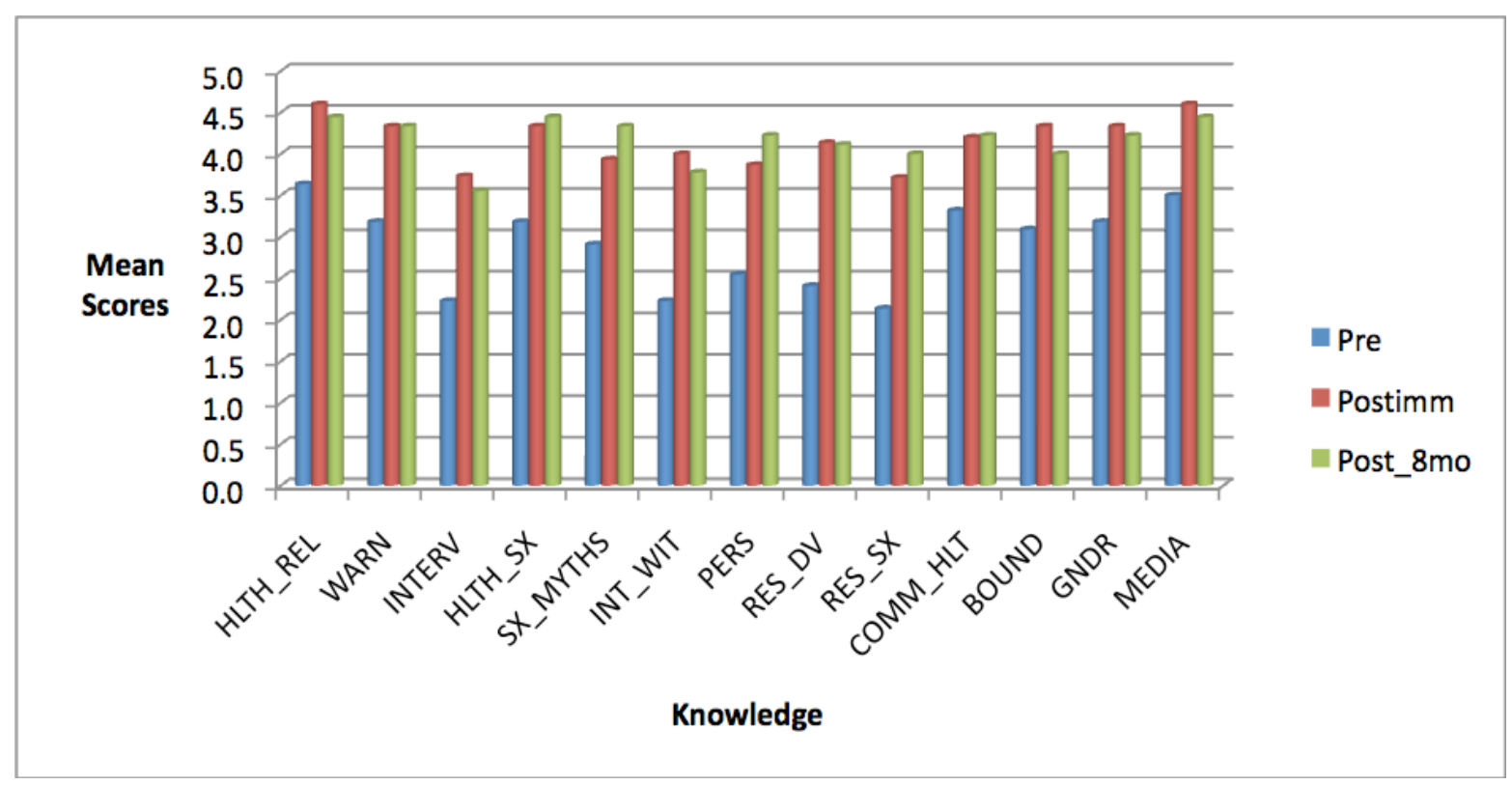

There were strong changes in almost all areas of knowledge after the workshop and related to key areas of dating violence: healthy relationships; sexual relationships; gender and media stereotypes; and boundaries and communication. These changes persisted across the eightmonth period. Levels of agreement/disagreement to specific measures within each of these modules supported the awareness and attitude changes, although in many instances these were not complete changes from disagreement to agreement or vice versa. Rather, these changes indicated level of intensity within the same category.

Limitations. A key limitation to the data analysis and findings was only being able to obtain nine respondents at the eight-month follow-up. Students were sent an e-mail reminding them of the survey and where it was located on-line. This low response rate at eight months could reflect bias in that, potentially, only those who experienced changes after the weekend event responded to the questionnaire. The magnitude and direction of the change, however, was similar to the immediate post measures in which we had 15 respondents, suggesting we may see similar results. Paired $t$-tests were not conducted as there were only nine respondents.

Another limitation is the self-selection of the participants. A number of these students had been victims of dating violence in some form, as evidenced by disclosures during the workshop. Although we observed increases in knowledge, the students may have had sufficient pre-existing knowledge such that significant changes in direction were not to be expected with respect to the questions related to knowledge and attitudes. 
International Journal of Child, Youth and Family Studies (2013) 1: 100-118

\section{Peer-facilitator Feedback}

To answer the research question, "What aspects of the program require modification?" we turned to the peer-facilitators for feedback; in addition, we maintained our own records as researchers. The researcher records were our own considerations of the process: what we thought worked or did not work, and our own challenges and strengths that we brought to the process. While both researchers and peer-facilitators claimed overall and general satisfaction with the program, there were particular aspects that require modification. Feedback from peer-facilitators was gathered during a focus group meeting at which 10 of the 15 facilitators were present. During this focus group peer-facilitators spoke about both positive and challenging aspects of the Stepping Up project.

In general, these facilitators experienced a great deal of personal fulfilment and gratification from having been involved with the project. For example, one particular facilitator stated, "it was an amazing experience and worth all the hard work”. Indeed, it was hard work for all involved, therefore, the feedback gathered will assist with future planning. The general themes for modification relate to time, practice, and preparation.

Time. The extent of time commitment is highly relevant to the post-secondary students. This concern about time related to both the peer-facilitators and the participants in the weekend program and the follow-up action plans. The peer-facilitators were concerned that they did not have enough time to adequately prepare the module activities, as one noted, "we spent a lot of time before we knew which module we were working on and then less time after we knew which module we were working on”. In other words, we spent a significant amount of time up front generating the content for the entire program, but less time on individual module and activity development.

These peer-facilitators also expressed the challenge that all group facilitators face, that being the issue of time as it relates to group processes. In particular, several peer-facilitators noted the lack of time during the module delivery for group process. For example, said one, "how can we get a really important message across in this amount of time? I don't think there was enough attention paid to how these people were going to process this information; to have enough time that they need to talk about how that information impacted them".

This sense that time was slipping away led to some to wonder about their skills and knowledge of group facilitation. They noted that the confidence the researchers had in their ability to lead a group assisted with their self-confidence: "I think the encouragement and continued e-mail encouragement and confidence in us was huge, because I don't think we would have done what we did without that confidence in us". We recognized early in the project that if we were to have a successful group we needed to take some responsibility as the leaders in maintaining the momentum, as well as boosting their self-belief as competent facilitators.

Further in this regard, the researchers thought that adequate time had been set aside for program development, which involved the inclusion of the National Coordinator of Making Waves. Students found their time with the coordinator to be invaluable and expressed appreciation for her knowledge and assistance, "J__ being there really helped, we could picture 
International Journal of Child, Youth and Family Studies (2013) 1: 100-118

what it could look like and get all the information ready to go". While time had been dedicated to content development and module activities, it became clear that the peer-facilitators needed significantly more time for developing their individual modules. Therefore, peers continued to meet at times that were convenient to their particular groups to complete the module development activities. As researchers, we each connected to different groups to assist with activities and to discuss issues of time as it related to the group process. We understood that these students were invested in the Stepping Up project, however we thought it was important to act as a link to create some accountability to the project since students could easily become weighed down by other priorities.

Based on this feedback and our own reflections about how the project unfolded, we agreed that, in order to assist with module development and activity planning, more full-group sessions were needed. For example, when the Making Waves National Coordinator, presented to the peer-facilitators, she demonstrated a number of potential activities that the peers could use in their modules. An entire day was dedicated to describing Making Waves and demonstrating activities. All peers stated that this was invaluable, with one stating, "I think the most helpful part for me was J_ _ being here, just to get an idea of how it's going to look”.

Another entire day was dedicated to module preparation with the coordinator's assistance. However, several of the peer-facilitator groups had difficulty with their own decisionmaking process and, therefore, needed significantly more time to decide what they wanted to do in their own modules. Several groups appreciated what had been shared from Making Waves, but wished to modify those activities to be more conducive to the post-secondary population, and needed time and space to do so.

Future implementation of the Stepping Up program will involve more time on the part of the researchers for teaching and modelling group process and decision-making. For example, while the facilitators did manage to meet and create appropriate module content and activity, scheduling a meeting became a challenge once they went their separate ways. Their dedication to this project was clear as demonstrated by their ability to fulfill their mandate; however, the researchers could have made this smoother by scheduling more group time upfront for both development and practice. The researchers, having visited the feedback from peer-facilitators, think it would be wise to set aside time during the training process, while we are available, for module planning and are, therefore, considering adding two more days to the training.

Practice and preparation. As the peer-facilitators commented on how the lack of time impacted their own sense of self as skilled group leaders, they began to recognize that preparation and practice would have assisted with their efficacy in this regard. As one said, for example, "we should have had a run through where everybody gets to practice and it would just build confidence". As noted by Corey and Corey (2006), becoming an effective group facilitator includes particular competencies which assist in the success of a group program. In the preparation for the peer-facilitators, the researchers set aside the recommended time for content development, module activity development, and a final meeting at which the facilitators shared their ideas for their particular module with the other peer-facilitators and the researchers. However, that final meeting was only half a day long, with limited time for alterations or adjustments to the module activities and no time allotted for the peers to practice facilitating their 
groups. Corey and Corey (2006) have noted several concerns for beginning group facilitators such as worry about mistakes, how to get started, and whether they have the knowledge and skill to handle what might emerge. Had there been time for a dry run with the peer-facilitators, we may have been better able to respond to their needs thereby increasing their confidence. In addition, during the focus group several commented that, had they had the time to practice with each other, feedback could have been shared in a safe environment prior to the event. As one individual noted, "we would have felt comfortable if we'd done a run through of the weekend, to give critical feedback to each other about the videos, or the exercise and activities."

The need for preparation and practice was highlighted during the event, particularly during one module when the very first question led to a personal disclosure of abuse, "I didn't expect it to happen so quickly because in our group the first thing, the first person shared a heavy, intense self-disclosure and I was just not prepared.” The peers who facilitated that particular group felt unprepared for this level of disclosure. During the focus group they disclosed feeling as though they had let some of the participants down since they were unsure about how to process these disclosures in the session.

Although the peer-facilitators had neither expected nor prepared for many disclosures, the student participants from the weekend event stated that the disclosures were a positive aspect of the program. Therefore, these researchers have noted the importance of assisting peers with skill development as it relates to the receiving of disclosures in a group context, recognizing, however, that such disclosures are neither encouraged nor related to the purpose of the program. During the weekend event, the Making Waves representative commented that such disclosures were not typical and not encouraged in their high school program. Nonetheless, disclosures may be more appropriate in post-secondary populations. The students were highly engaged and verbal throughout the entire weekend. Given that most of the participants seemed comfortable with the disclosures, it may be that the facilitators simply need more preparation about the unpredictability of group process.

In sessions prior to the weekend, the researchers could have acted as participants and had the facilitators practice managing certain group dynamics. It may be that given the amount of time we had spent with the facilitators, that we had become comfortable with their skill level, but had not remembered what it is like to facilitate a group for the first time. Because the majority of the facilitators were from human service programs, we may have made assumptions about the skills developed through their own program courses. One group facilitation course is not likely to plant deep-seated confidence. In the future, we would ensure that there is time set aside to practice facilitating their modules.

Prevention projects. The undergraduate student participants continued to meet in small groups with their peer-facilitators post-program to plan and implement prevention projects for the campus community. Projects include posters, T-shirts, bookmarks, buttons, brochures, and radio advertisements. At the end of the weekend, most participants expressed excitement about engaging in awareness projects for their campus. However, much like any weekend retreat, people are excited during the event, but a return to their busy stressful lives, particularly as students, means these added duties may fall to the wayside. Regardless, many students remained involved and created small cohorts and worked together to produce these projects. 
International Journal of Child, Youth and Family Studies (2013) 1: 100-118

Two peer-facilitators were assigned to oversee, monitor, and maintain contact with the weekend participants to assist with project completion. The other peer-facilitators worked along with the groups to assist in completing the projects and communicate with the researchers as necessary. The peer-facilitators described this as the most challenging aspect of the program, with one observing, "it was frustrating trying to get a hold of group members and then it was stressful too because I wanted it to be successful." Listening to them at the focus group describe the process for completing the projects, we had visions of herding cats.

Feedback about the project aspect of the Stepping Up program as compared to the Making Waves community projects focused on the differences in the populations. The peerfacilitators were clear that university students may not appreciate the added stressor of this expectation. Said one, "Making Waves [community projects] may not work for university. Students are socially different; they are developmentally different. This is extra-curricular, so if you have a big paper due or something worth marks that's always going to take priority." While we believe these awareness-building projects are vital for the campus community, there may be ways to structure the projects to lighten the load, such as providing a list of achievable ideas from which to choose.

\section{Discussion}

Changing the beliefs and attitudes of abuse and violence held by both university undergraduate students and faculty members is a long-term process. Conflicting demands on peer-facilitators' and participants' time made it challenging for all of the students to engage in all aspects of the project. For students in Social Work and Child and Youth Studies, faculty recognized the value of the project and helped to support student involvement through a variety of creative strategies such as credit towards practicum/field placement hours for time spent involved in the Stepping Up project.

The focus of the project became the development of peer-facilitators as group leaders and the context of the curriculum rather than specific content of the curriculum for each module. This was a notable difference between Making Waves and Stepping Up for post-secondary students and was later confirmed by the National Coordinator of Making Waves. However, the large improvements in self-reported knowledge from students who completed the pre, post, and follow-up KABBI surveys suggested that providing an opportunity for participants to talk about the content areas is important, even outside of specific or standardized curriculum content. The number of observed self-disclosures was also greater than expected. This could reflect the design of the program, that a number of the participants knew each other, or that the previous experience of abuse was a factor in self-selection.

The positive support for the weekend length and the knowledge gains of participants provided strong support of a peer-facilitated model given the busy lives of students and the challenges of them finding three days over a weekend to participate. This also suggests the 
importance of giving students an opportunity to discuss these topic areas and consolidation of learning through the community prevention projects.

Limitations of the weekend included the number of students who participated (i.e., weather was a significant issue, greatly cutting attendance at the last minute), an overrepresentation of student participants from one program, and access to funding to support both the immediate and long-term evaluations. The students were predominantly from two programs already familiar with abuse issues (Social Work and Child and Youth Studies) and more than half received credit for hours attended. This may have had an effect on the positive nature of the results, although the difference in KABBI scores would suggest they were not all as familiar with the key issues as anticipated. The availability of long-term funding that extends from the development through an eight-month follow-up evaluation is also a potential limitation. The Stepping Up researchers were able to secure funding to support all phases of the project; however, continuous funding from one source is always the ideal.

Areas to consider in the future concern the time allocated for training peer-facilitators, the timing of the prevention weekend, and added training specific to responding to disclosures. Discussions on training methods, the need for specific content objectives, and how to encourage faculty from other programs to support student involvement will be ongoing. A second pilot is planned for September 2012, pending funding, and will incorporate the current findings. 
International Journal of Child, Youth and Family Studies (2013) 1: 100-118

\section{References}

Amar, A. F. (2007). Dating violence: Comparing victims who are also perpetrators with victims who are not. Journal of Forensic Nursing, 3(1), 35-41.

Amar, A. F., \& Gennaro, S. (2005). Dating violence in college women: Associated physical injury, healthcare usage, and mental health symptoms. Nursing Research, 54(4), 235242.

Arnett, J. J. (2004). Emerging adulthood: The winding road from the late teens through the twenties. New York, NY: Oxford University Press.

Cameron, C. A., Byers, S., Miller, S. A., McKay, S. L., St. Pierre, M., \& Glenn, S. (2007). Violence prevention in New Brunswick. Fredericton: Status of Women Canada.

Campbell, J. C., Sharps, P., Laughon, K., Webster, D., Manganello, J., Schollenberger, J., et al. (2003). Risk factors for femicide in abusive relationships: Results from a multisite case control study. American Journal of Public Health, 93(7), 1089-1098.

Casey, E., \& Lindhorst, T. P. (2009). Toward a multi-level, ecological approach to the primary prevention of sexual assault. Trauma, Violence \& Abuse, 10(2), 91-114.

Centre for Disease Control. (2007). Social ecological model. CDC violence prevention. Retrieved September 7, 2010 from http://www.cdc.gov/ncipc/dvp/social-ecologicalmodel_dvp.htm

Corey, M., \& Corey, G. (2006). Groups: Process and practice. Toronto: Thomson Learning.

Danis, F. S., \& Anderson, K. M. (2008). An underserved population and untapped resource: A preliminary study of collegiate sorority response to dating violence. Journal of Aggression, Maltreatment and Trauma, 17(3), 336-351. doi: 10.1080/10926770802406478

Department of Justice. (2003). Dating violence fact sheet. Ottawa: Author. Retrieved October 2, 2009 from http://canada.justice.gc.ca/eng/pi/fv-vf/facts-info/dati-freq.html

Erikson, E. H. (1985). Childhood and society. New York: W.W. Norton \& Company.

Forbes, G. B., \& Adams-Curtis, L. E. (2001). Experiences with sexual coercion in college males and females: Role of family conflict, sexist attitudes, acceptance of rape myths, selfesteem, and the big-five personality factors. Journal of Interpersonal Violence, 16(9), 865-889. 
International Journal of Child, Youth and Family Studies (2013) 1: 100-118

Johnson, H. (2006). Measuring violence against women: Statistical trends 2006. Ottawa: Statistics Canada.

Legge, R., Josephson, W. L., Hicks, C., \& Kepron, L. (2004). Dating violence: Effects of the Canadian Red Cross prevention program: What's love got to do with it? In C. A. Ateah \& J. Mirwaldt (Eds.), Within our reach: Preventing abuse across the lifespan (pp. 61-75). Winnipeg, MB: Fernwood.

McFarlane, J., Malecha, A., Watson, K., Gist, J., Batten, E., Hall, I., \& Smith, S. ( 2005). Intimate partner sexual assault against women: Frequency, health consequences, and treatment outcomes. Obstetrics \& Gynecology, 105(1), 99-108. doi: 10.1097/01.AOG.0000146641.98665.b6

Silverman, J. G., Raj, A., Mucci, L. A., \& Hathway, J. E. (2001). Dating violence against adolescent girls and associated substance use, unhealthy weight control, sexual risk behavior, pregnancy and suicidality. Journal of the American Medical Association, 286(5), 572-579.

Simonelli, C. J., Mullis, T., Elliot, A. N., \& Pierce, T. W. (2002). Abuse by siblings and subsequent experiences of violence within the dating relationship. Journal of Interpersonal Violence, 17(2), 103-121.

Smith, P. H., White, J. W., \& Holland, L. J. (2003). A longitudinal perspective on dating violence among adolescent and college-age women. American Journal of Public Health, 93(7), 1104-1109.

Straus, M. A. (2004). Prevalence of violence against dating partners by male and female university students worldwide. Violence Against Women, 10(7), 790-811.

Straus, M. A., \& Savage, S. A. (2005). Neglectful behavior by parents in the life history of university students in 17 countries and its relation to violence against dating partners. Child Maltreatment, 10(2), 124-135.

Tutty, L. M. (2010). Do dating violence and healthy relationship programs make a difference? Toronto: Canadian Women's Foundation.

Tutty, L., \& Bradshaw, C. (2003). Violence against women and girls: Why should I care? Toronto, ON: Canadian Women’s Foundation. Retrieved July 20, 2007 from http://www.cdnwomen.org/eng/1/index.asp

Tutty, L. M., Bradshaw, C., Thurston, W. E., Barlow, A., Marshall, P., Tunstall, L., et al. (2005). School-based violence prevention programs: A resource manual. Calgary, AB: RESOLVE Alberta. Online at www.ucalgary.ca/resolve/violenceprevention/ 
International Journal of Child, Youth and Family Studies (2013) 1: 100-118

Walton-Moss, B., Morrison, C., Yeo, T., Woodruff, K., Woods, N., Campbell, J., et al. (2003). Interrelationships of violence and psychiatric symptoms in women with substance use disorders. Journal of Addictions Nursing, 14(4), 193-200.

Warthe, D. G. (2011). The development of the Dating Relationship Scales for young adults. Doctoral dissertation, Faculty of Social Work, University of Calgary, AB.

Warthe, D. G., Hoffart, I. \& Cooper, M. (2004). Calgary family and sexual violence sector review: Building a new vision. Written for The City of Calgary Community Strategies, The United Way of Calgary and Area, and Calgary and Area Child and Family Services Authority.

Warthe, D. G., \& Tutty, L. M. (2008, November). Dating violence at Mount Royal College, Calgary. RESOLVE Research Day 2008, Winnipeg, MB.

Warthe, D. G., \& Tutty, L. M. (2009). College dating violence: Correlations with health and risk behaviours. $14^{\text {th }}$ International Conference on Violence, Abuse and Trauma, San Diego, CA.

Warthe, D. G., \& Tutty, L. M. (2010, November). Manifestations of sex and gender: Using survey data to understand the gendered experience of violence. RESOLVE Research Day, Calgary, AB.

Wolfe, D. A., Wekerle, C., Scott, K., Straatman, A., Grasley, C., \& Reitzel-Jaffe, D. (2003). Dating violence prevention with at-risk youth: A controlled outcome evaluation. Journal of Consulting and Clinical Psychology, 71(2), 279-291. 